\title{
A exegese legislativa acerca da ventilação urbana: proposição de sistema para avaliação de adequabilidade
}

\author{
SILVA, Fabiana Trindade da ${ }^{1}$ \\ ALVAREZ, Cristina Engel de \\ ${ }^{1}$ Universidade Federal do Espírito Santo, Vila Velha, Brasil. fabianatrindade.silva@gmail.com
}

\section{Resumo}

O Plano Diretor é indicado tanto pela Constituição Federal de 1988 (BRASIL, 2013) quanto pelo Estatuto da Cidade de 2001 (BRASIL, 2012) como instrumento básico de expansão urbana. Cabe a este a função de intervir no processo de desenvolvimento local a partir da compreensão integradora dos diversos fatores que influem na dinâmica citadina, dentre eles os fatores ambientais. Nas cidades litorâneas de clima tropical úmido, como é o caso do município de Vitória (ES), a ventilação natural se destaca como um recurso desejável na mitigação do desconforto térmico. Dessa forma o objetivo desta pesquisa foi a proposição de um sistema para cognição da exegese legislativa concernente às questões de ventilação natural urbana contida nos planos diretores urbanos, cuja aplicação inicial baseia-se na realidade do município de Vitória, capital do Espírito Santo. A metodologia utilizada constitui-se em 03 (três) etapas: a primeira trata do levantamento teórico e experimental; a segunda é caracterizada pela estruturação do método; e a etapa final diz respeito à aplicação do sistema para uma área de amostra assim como a discussão dos resultados encontrados. Os resultados obtidos apontam que o sistema proposto demonstrou resultados satisfatórios em seu primeiro teste de aplicabilidade, sendo capaz de identificar os itens que necessitam de revisão e os que devem ser mantidos. Na aplicação inicial para o PDU (Plano Diretor Urbano) de Vitória (ESPÍRITO SANTO, 2012) constatou-se que os critérios para utilização do sistema são adequados e recomenda-se a realização de novos testes visando seu aperfeiçoamento.

Palavras-Chave: ventilação urbana, plano diretor, sistema de avaliação.

\begin{abstract}
The Master Plan is indicated both by the Constitution of 1988 (BRAZIL, 2013) as by the City Statute of 2001 (BRAZIL, 2012) as a basic instrument of urban sprawl. It is their function to intervene in the process of local development from the integrative understanding of the various factors that influence the dynamic city, including environmental factors. In the coastal cities of humid tropical climate, such as the city of Vitória (ES), natural ventilation stands as a desirable feature in mitigating the thermal discomfort. Thus the aim of this research was to propose a system for cognition of the legislative exegesis issues concerning urban natural ventilation contained in urban master plans, whose initial implementation is based on the reality of the city of Vitória, capital of Espírito Santo. The methodology consists in 03 (three) stages: the first deals with the theoretical and experimental survey, the second is characterized by structuring the method, and the final step concerns the application of the system to a sample area as well as the discussion of results. The results indicate that the proposed system showed satisfactory results in its first test of applicability, being able to identify items that need revision and should be maintained. In the initial application for the PDU (Urban Master Plan) of Vitória (ESPÍRITO SANTO, 2012) found that the criteria for use of the system are adequate and new tests are recommended aiming its improvement.
\end{abstract}

Keywords: urban ventilation, master plan, evaluation procedure. 


\section{Introdução}

A expansão da malha urbana associada à verticalização e adensamento das estruturas citadinas condicionam o clima urbano e, consequentemente, impactam nas condições de conforto térmico da população. Essas modificações das configurações urbanas afetam o conforto tanto no ambiente externo (meio urbano), quanto no ambiente interno (interior das edificações), pois interferem nas variáveis climáticas alterando suas grandezas, formando um mosaico de microclimas, do qual o clima urbano é composto.

O clima urbano está diretamente relacionado à saúde e ao bem-estar do ser humano, sendo caracteristicamente um produto da interação dos diferentes elementos atmosféricos, como a temperatura do ar, a umidade e o vento estabelecidos a partir de um complexo térmico e da composição da tipologia urbana. Os estudos climáticos no meio urbano têm sido realizados por pesquisadores em várias localidades do mundo, tendo em vista que as cidades formam aglomerados urbanos crescentes e esses tem exercido grande influência na mudança de temperatura e na ventilação natural (ALCOFORADO e ANDRADE, 2007).

A configuração urbana da cidade formal é definida pelos valores dos índices urbanísticos estabelecidos nos planos diretores municipais. A Constituição Federal de 1988 (BRASIL, 2013), assim como o Estatuto da Cidade de 2001 (BRASIL, 2012) determinam o Plano Diretor como o instrumento básico de expansão e desenvolvimento urbano. O Estatuto da Cidade define o município como responsável pela política urbana, sendo portanto da municipalidade o encargo de construção do Plano Diretor Urbano (PDU) - obrigatório para cidades com população acima de 20 mil habitantes -, destacando-se que este deve ser aprovado por lei municipal.

Além da exigência constitucional, a crescente expansão urbana observada nas cidades brasileiras reafirma o papel do planejamento local como importante instrumento para organização das ações governamentais, visando o bem-estar coletivo. Cabe ao Plano Diretor a função de intervirno processo de desenvolvimento local a partir da compreensão integradora dos diversos fatores que influem na dinâmica citadina, dentre eles os fatores ambientais.

Sendo assim, o crescimento das cidades associado à falta de inclusão de elementos climáticos nos instrumentos de planejamento urbano geram consequências ambientais que contribuem para o agravamento das modificações climáticas, especialmente no que diz respeito ao comportamento do ar em movimento. Dessa forma, se faz necessário o entendimento dos efeitos climáticos originados pelas modificações da estrutura urbana para estabelecer medidas de mitigação do desconforto térmico localizado.

O adequado tratamento das variáveis climáticas no planejamento urbano, a partir da compreensão de suas interações com o meio urbano é fundamental para garantia do conforto ambiental. Ressalta-se que dos impactos sofridos pelas variáveis climáticas, a mudança da direção e velocidade do vento, associados a essas alterações do ambiente urbano é um dos fatores que mais condiciona o clima das cidades (LOPES e VASCONCELOS, 2006). Observa-se que para determinadas condições ambientais, o vento pode ser um elemento climático capaz de atenuar o efeito das ilhas de calor urbano e promover o necessário arejamento.

As condições de ventilação urbana adequadas para cada localidade são, na maioria dos casos, essenciais para se obter um bom nível de qualidade do ar nas metrópoles, especialmente considerando que nos últimos anos os níveis de poluição gerados pelo aumento de automóveis nas ruas vêm se agravado. A eficiência da ventilação urbana depende da interação do vento em diversas escalas e das características naturais e artificiais das cidades, cujo planejamento deve intervir para promover o arejamento necessário e, assim, otimizar as condições de conforto dos citadinos.

Nas cidades litorâneas de clima tropical úmido, como é o caso do município de Vitória (ES), a ventilação natural se destaca como um recurso bastante desejável na mitigação do desconforto térmico típico deste clima, pois provoca sensação de alívio térmico. Situada no litoral brasileiro, Vitória recebe influência direta dos ventos alísios marítimos, o que torna de suma importância a observação da trajetória do vento, visto que este é um valoroso agente de amenização climática.

De acordo com os dados obtidos através de observações dos normais climatológicos do INMET (acesso em 15 mar. 2013) para a última década, a cidade de Vitória é caracterizada por temperatura média do ar de $25,3^{\circ} \mathrm{C}$, apresentando temperatura mínima média de $21,7^{\circ} \mathrm{C}$; temperatura máxima média de $28,8^{\circ} \mathrm{C}$ e umidade em $77 \%$. A partir desses dados ressalta-se a importância da ventilação para promover o necessário arejamento e amenizar o excesso de umidade, removendo vapores e evitando a saturação do ar estagnado. 


\section{Objetivo}

Esta pesquisa teve como objetivo a proposição de um sistema para cognição da exegese legislativa concernente às questões de ventilação natural urbana contidas nos planos diretores urbanos, cuja aplicação inicial baseia-se na realidade do município de Vitória, capital do Espírito Santo.

\section{Procedimentos Metodológicos}

A partir do entendimento do papel do PDU na construção da configuração urbana e da importância da ventilação urbana para o alcance do conforto ambiental para o contexto climático de Vitória, é desejável a avaliação desse diploma legal para a identificação dos itens que precisam ser aprimorados, revistos ou inclusos para alcançar uma melhor qualidade do ambiente construído.

Para a avaliação dos instrumentos do Plano Diretor é proposto um sistema, cujos critérios são estabelecidos a partir de conceituações e experimentos realizados por autores como Cândido e Bittencourt (2008), Romero (2000),
Oke e Grimmond (1999), Oke (2006), e Mascaró (2004).

Os procedimentos metodológicos adotados para a pesquisa foram divididos em 03 (três) etapas fundamentais: a primeira constitui no levantamento teórico e experimental; a segunda trata da estruturação do sistema de avaliação e a etapa final diz respeito à aplicação deste para uma área de amostra assim como para a discussão dos resultados encontrados. A síntese metodológica é representada na Figura 1.

\subsection{Primeira etapa: revisão bibliográfica}

Essa etapa subdivide-se em três fases, sendo a primeira referente à revisão bibliográfica para levantamento das conceituações e experimentos inerentes às questões climáticas, de ventilação urbana, da legislação urbanística e dos métodos de análise que irão nortear as fases subsequentes. $\mathrm{Na}$ segunda fase foram identificados os aspectos da configuração urbana que influenciam a variável climática em análise, ou seja, o vento. $\mathrm{Na}$ terceira fase, os aspectos identificados na fase anterior foram hierarquizados de acordo com o grau de

Figura 1: Síntese dos procedimentos metodológicos

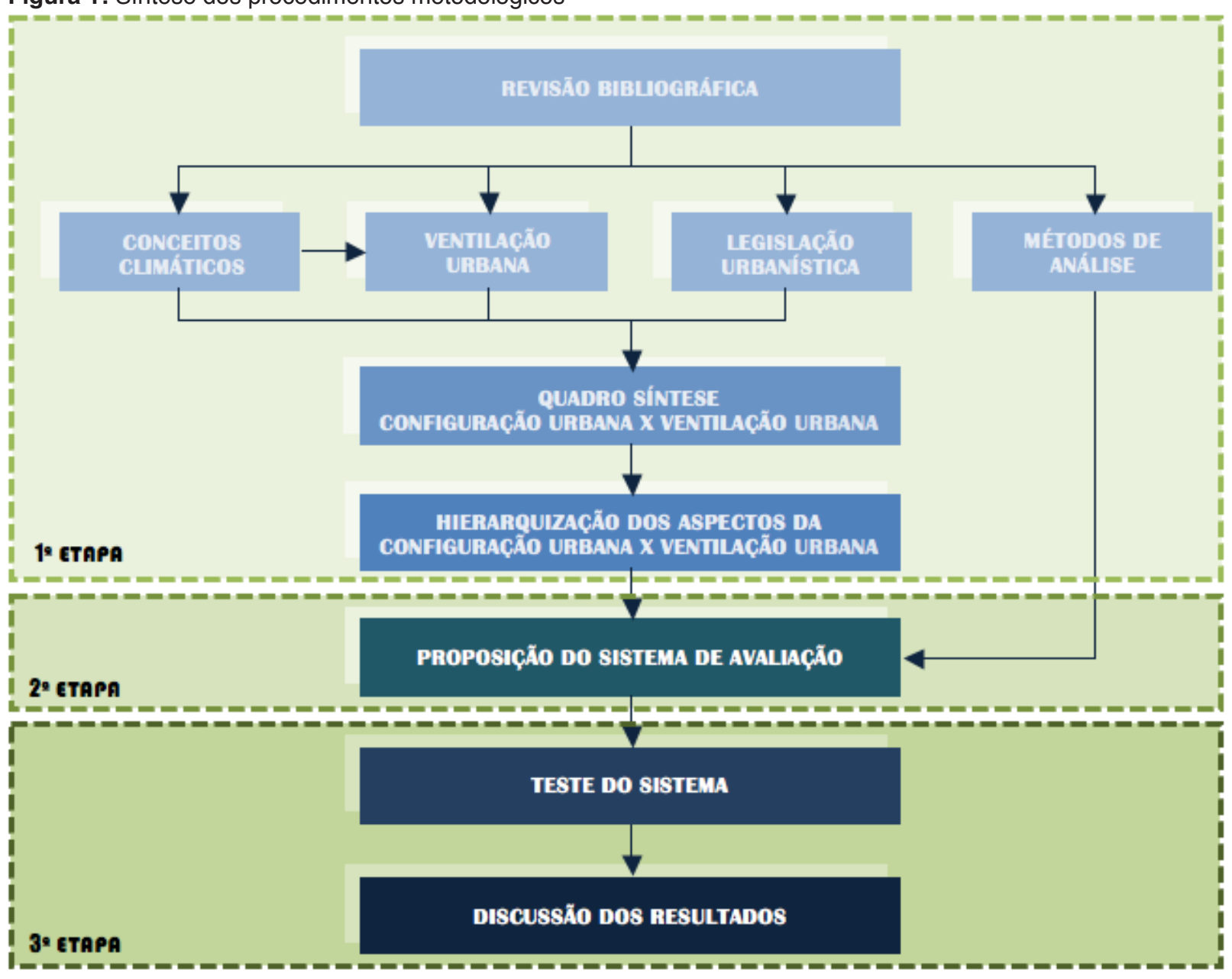


influência que esses exercem na ventilação urbana, destacando-se que essa hierarquia serve de parâmetro para a atribuição de valores percentuais estabelecidos na etapa seguinte.

\subsection{Segunda etapa: sistema de avaliação}

São considerados elementos textuais a Concomitante às definições da etapa anterior, foi estruturado o quadro para avaliação do Plano Diretor quanto às questões referentes à ventilação natural urbana. Para a utilização do sistema foram estabelecidas diretrizes norteadoras e selecionados parâmetros para sua aplicação, estabelecidos a partir do referencial teórico e das pesquisas experimentais levantadas na primeira etapa. Sendo assim, determina-se que o quadro para avaliação deve ser aplicado para cada zona urbanística definida pelo Plano Diretor em análise.

Através da atribuição de valores percentuais, foi estabelecido um valor mínimo percentual para o Plano Diretor ser avaliado como adequado em relação ao foco de análise. Esse valor mínimo foi estabelecido de forma que para alcançá-la fazse necessário pontuar, mesmo que minimamente, os itens que foram identificados pela etapa anterior como de maior impacto na ventilação natural. Como principal estratégia para o alcance dos resultados, foram atribuídos pesos diferenciados para cada item, sendo valorizados aqueles de maior interferência no fluxo e intensidade da ventilação natural.

\subsection{Terceira etapa: teste, análise dos da- dos e resultados}

A última etapa diz respeito à aplicação do sistema para uma área de amostragem, com o intuito de exemplificar sua utilização e realizar a análise dos institutos concernentes à ventilação urbana no Plano Diretor Urbano de Vitória. Para a exemplificação do método foi definido como área de análise uma seção do território do município de Vitória, sendo essa representada pela extensão territorial que corresponde ao bairro Mata da Praia.

Identificou-se a localização do bairro no mapa de zoneamento urbanístico, constante no Anexo 2 (Delimitação do Zoneamento Urbanístico) do PDU de Vitória. A Mata da Praia é composta por 03 (três) zonas distintas: a ZOC3 (Zona de Ocupação Controlada); a ZPA2 (Zona de Proteção Ambiental); e a ZOR/09 (Zona de Ocupação Restrita). Após a aplicação do sistema para todas as zonas foram apresentados, analisados e discutidos os resultados encontrados mediante a utilização do sistema.

\section{Resultados}

Assim como os procedimentos metodológicos foram articulados em 03(três) etapas, a apresentação dos resultados segue a mesma composição. Dessa forma, os resultados são apresentados por etapas, observando-se que a primeira etapa converteu-se em dois subprodutos: o quadro síntese de influência dos aspectos da configuração urbana na ventilação natural, e a listagem hierárquica desses aspectos.

A segunda etapa tem como produto o sistema de avaliação, objeto principal da pesquisa. Este sistema é estruturado em um quadro que auxilia a análise do Plano Diretor, e na proposição de regulamentações para sua aplicação. A terceira e última etapa diz respeito ao teste do sistema, observando que a mesma foi aplicada para duas zonas urbanísticas do PDU de Vitória (ES) com o objetivo de ilustrar seu funcionamento. Sequencialmente são discutidos os resultados obtidos.

\subsection{Primeira etapa: definição dos aspec- tos da configuração urbana $x$ ventilação natural}

Baseados nos conceitos, análises e constatações de Higueras (2006), Gartland (2010) e Romero (2000) foram definidos os aspectos referentes à tipologia urbana que influenciam de forma mais efetiva na ventilação natural, sendo esses responsáveis pela alteração de suas grandezas, como a diminuição de sua velocidade e alteração de sua direção. O Quadro 1 sintetiza as características da tipologia urbana e como essas influenciam na ventilação.

Dentre os aspectos da configuração urbana que exercem influência na ventilação natural, destacam-se:

1. Porosidade da malha urbana: apontado como responsável pelo permeio da ventilação entre as quadras (MASCARÓ, 2004; CÂNDIDO e BITTENCOURT, 2008; ROMERO, 2000; MARQUES, 2003; LEITE, 2008). A porosidade no meio urbano é definida pelos afastamentos entres os elementos edificados, podendo ser tanto os laterais, frontais, de fundos, como os afastamentos gerados pela taxa de ocupação máxima permitida. Também as 
Quadro 1: Influência das condicionantes do assentamento urbano na ventilação

\begin{tabular}{|l|l}
\multicolumn{1}{|c}{ Aspectos da tipologia urbana } & \multicolumn{1}{c}{ Influência na ventilação } \\
\hline $\begin{array}{l}\text { Orientação e declividade } \\
\text { Proximidade de massas de água }\end{array}$ & Velocidade e direção \\
\hline $\begin{array}{l}\text { Condicionantes do posicionamento geográfico de um determinado } \\
\text { local: latitude e altitude }\end{array}$ & $\begin{array}{l}\text { Classe de vento } \\
\text { Brasil: alísios de sudeste }\end{array}$ \\
$\begin{array}{ll}\text { Orientação das quadras, lotes e edificações; disposição e dimensões das } \\
\text { vias; densidade construída; espaços públicos }\end{array}$ & $\begin{array}{l}\text { Celocidade } \\
\text { Vegetação: disposiçãão nas vias, bloqueio ou permeio da }\end{array}$ \\
\hline Vespaços públicos e no interior dos lotes & Condução, bloqueio \\
\hline
\end{tabular}
vias funcionam como canais de ventilação.

2. Rugosidade urbana: responsável pelo incremento do movimento do ar entre as edificações (OKE, 2006; ROMERO, 2000). A rugosidade é produto dos gabaritos, das alturas das edificações e do coeficiente de aproveitamento máximo.

3. Densidade construída: possibilita ou dificulta o movimento do ar no meio urbano. Nas áreas mais adensadas são registradas temperaturas do ar maiores, quando formam blocos que funcionam como barreira à ventilação (ROMERO, 2000; OKE, 2006). A densidade construída é resultante dos índices taxa de ocupação, coeficiente de aproveitamento, afastamentos, altura e gabarito.

4. Vegetação: bloqueia, conduz ou filtra os ventos. A disposição da vegetação em climas tropicais úmidos também é importante para o sombreamento, que tanto auxilia no conforto dos transeunte como pode auxiliar na movimentação do ar pelas diferenças de temperaturas (BITTENCOURT e CÂNDIDO, 2008; ROMERO, 2000; MASCARÓ, 2004).

5. Disposição de áreas abertas: a presença de áreas abertas em meio ao ambiente construído - como praças e parques -, cria zonas onde o vento pode recuperar sua velocidade alterada pelos elementos construídos (BITTENCOURT E CÂNDIDO, 2008; ROMERO, 2000; MASCARÓ, 2004).

Atenta-se ainda para mais uma importante questão a ser analisada no que concerne à ventilação natural: o comportamento do vento na camada atmosférica. Como já mencionado anteriormente o vento é impactado tanto pela porosidade quanto pela rugosidade da tipologia urbana. Isso significa que o vento distante dos efeitos superficiais, apresenta um perfil de velocidade vertical aproximadamente constante, contudo, o vento ao se aproximar do solo tem sua velocidade reduzida, criando assim um gradiente de velocidade (MARQUES, 2003), como pode ser observado na Figura 2.
Figura 2: Gradiente de velocidade influenciado pela rugosidade

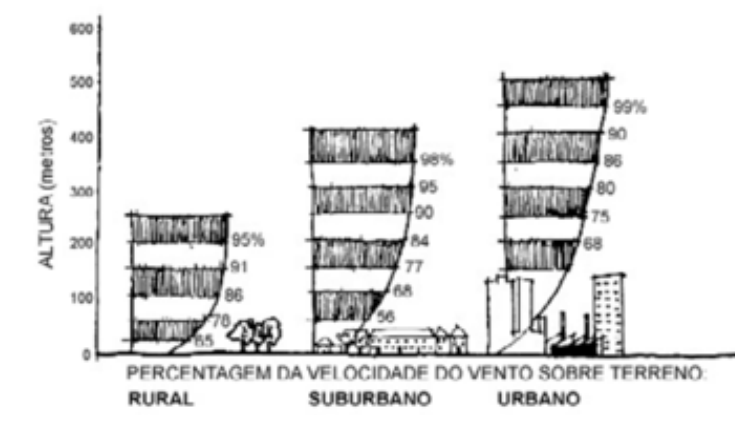

Fonte: Marques (2003) adaptado de Mascaró (1996).

Dessa forma ressalta-se a importância de garantir a porosidade urbana especialmente no nível do transeunte, considerando ser esse o nível de maior prejuízo nos aglomerados urbanos.

\subsection{Segunda etapa: proposta de sistema para avaliação}

O sistema proposto foi estruturado a partir de um quadro síntese (Quadro 2) que baseia-se na identificação dos itens que impactam a ventilação urbana, devendo inicialmente ser assinalado se este está ou não contido no Plano Diretor. Em seguida deve-se identificar na coluna referente ao peso o valor alcançado, sendo que se o item está contido no PDU recebe o valor cheio, e se não está, recebe valor nulo. Não foram definidas situações passíveis de escalonamento de variação numérica. Para cada item podem ser anotadas no quadro, especificidades que auxiliem a discussão dos resultados.

Para a avaliação do Plano Diretor a partir do quadro foi estabelecido o limite de $60 \%$ como margem mínima para o Plano ser considerado adequado, sendo esse o valor atribuído em função da porcentagem obtida na quantificação total, e devendo esse mínimo ser obtido em cada zona urbanística definida pelo PDU. Para atingir o valor mínimo de $60 \%$ é preciso que o Plano 
Quadro 2: Sistema para avaliação do Plano Diretor Urbano (PDU) em relação à ventilação

\begin{tabular}{|c|c|c|c|c|}
\hline \multicolumn{5}{|c|}{ QUADRO PARA AVALIAÇÃO } \\
\hline \multicolumn{2}{|r|}{ ITEM A SER ANALISADO } & \multirow{2}{*}{ SIM } & \multirow[t]{2}{*}{ ESPECIFICIDADES } & \multirow{2}{*}{ PESO } \\
\hline 1 & $\begin{array}{l}\text { O coeficiente de aproveitamento (CA) e o } \\
\text { gabarito máximos são estipulados de forma } \\
\text { que para alcançar o máximo em ambos os } \\
\text { índices se faz necessário reduzir a taxa de } \\
\text { ocupação máxima permitida }\end{array}$ & & & \\
\hline 2 & $\begin{array}{l}\text { A taxa de ocupação (TO) máxima é menor } \\
\text { ou igual a } 60 \%\end{array}$ & & & $15 \%$ \\
\hline 3 & $\begin{array}{l}\text { Prevê dispositivos de redução tributária se a } \\
\text { taxa de ocupação for } 20 \% \text { menor que a } \\
\text { máxima permitida por zona. (Exemplo: } \\
\text { isenção do pagamento da taxa de alvará de } \\
\text { construção). }\end{array}$ & & & $5 \%$ \\
\hline 4 & $\begin{array}{l}\text { Estabelece valor mínimo para afastamento } \\
\text { frontal }\end{array}$ & & & $5 \%$ \\
\hline 5 & $\begin{array}{l}\text { Estabelece valor mínimo para afastamento } \\
\text { frontal nos } 3 \text { primeiros pavimentos } \\
\text { (incluindo o meio-subsolo) }\end{array}$ & & & $10 \%$ \\
\hline 6 & $\begin{array}{l}\text { Estabelece valor mínimo para afastamento } \\
\text { lateral }\end{array}$ & & & $5 \%$ \\
\hline 7 & $\begin{array}{l}\text { Estabelece valor mínimo para afastamento } \\
\text { lateral nos } 3 \text { primeiros pavimentos (incluindo } \\
\text { o meio-subsolo) }\end{array}$ & & & $10 \%$ \\
\hline 8 & $\begin{array}{l}\text { Estabelece valor mínimo para afastamento } \\
\text { de fundos }\end{array}$ & & & $5 \%$ \\
\hline 9 & $\begin{array}{l}\text { Estabelece valor mínimo para afastamento } \\
\text { de fundos nos } 3 \text { primeiros pavimentos } \\
\text { (incluindo o meio-subsolo) }\end{array}$ & & & $5 \%$ \\
\hline $\begin{array}{l}1 \\
0\end{array}$ & $\begin{array}{l}\text { Prevê manutenção de vias que funcionem } \\
\text { como canais de ventilação }\end{array}$ & & & $10 \%$ \\
\hline $\begin{array}{l}1 \\
1\end{array}$ & $\begin{array}{l}\text { As vias são dimensionadas em função da } \\
\text { taxa de densidade das quadras paralelas a } \\
\text { estas }\end{array}$ & & & $5 \%$ \\
\hline $\begin{array}{l}1 \\
2\end{array}$ & $\begin{array}{l}\text { Identifica a preservação/incentivo de } \\
\text { espaços abertos }\end{array}$ & & & $5 \%$ \\
\hline $\begin{array}{l}1 \\
3\end{array}$ & $\begin{array}{l}\text { Prevê e/ou incentiva o plantio de vegetação } \\
\text { de grande porte }\end{array}$ & & & $5 \%$ \\
\hline & & & Quantificação tot & \\
\hline & $\begin{array}{l}\text { SERVAÇÕES: } \\
\text { tem 1: não é necessária a definição do coefi } \\
\text { pulado o número máximo de pavimentos(gabarit } \\
\text { t. } \\
\text { tem 3: pode-se considerar adequado quando } \\
\text { tens } 4,6 \text { e } 8 \text { : excetua-se a análise desses qua } \\
\text { s) pavimentos ou menos. Quando esse for o } \\
\text { em ser redistribuídos nos itens } 1 \text { e } 2 \text {. Dessa for } \\
2 \text { passa a ter peso de } 25 \% \text {. } \\
\text { tem 12: a avaliação de adequação refere-se a m } \\
\text { lência do bairro e não da zona. Para análise d } \\
\text { eamento urbanístico. Os espaços abertos no Pl } \\
\text { as de Proteção Ambiental e a essas não se aplic }\end{array}$ & $\begin{array}{l}\text { iente de } \\
\text {, e a tax } \\
\text { taxa de } \\
\text { do o gab } \\
\text { aso, os } \\
\text { la o item } \\
\text { anutençã } \\
\text { sse item } \\
\text { no Direto }\end{array}$ & $\begin{array}{l}\text { oveitamento máxim } \\
\text { ocupação máxima i } \\
\text { pação máxima for ir } \\
\text { máximo permitido } \\
\text { es atribuídos a ess } \\
\text { assa a ter peso de } \\
\text { espaços abertos no } \\
\text { e ser observado o n } \\
\text { dem ser classificad } \\
\text { roposto. }\end{array}$ & $\begin{array}{l}\text { e for } \\
\text { rior a } \\
\text { rior a } \\
\text { de } 3 \\
\text { itens } \\
\% \text { e } 0 \\
\text { io de } \\
\text { a de } \\
\text { como }\end{array}$ \\
\hline
\end{tabular}

contenha minimamente os itens que garantam a porosidade da configuração urbana, tais como a taxa de ocupação e afastamentos.

Ressalta-se que a aplicação desse quadro refere-se à análise inicial dos aspectos apontados como fundamentais de acordo com o referencial teórico adotado, podendo ser identificados aspectos que devem ser aprimorados, revistos ou inclusos. Adverte-se 
que para a conversão desses itens em índices de controle urbanístico com valores definidos como máximos ou mínimos nos PDU's são necessários estudos aprofundados para adequálos ao contexto climático de cada cidade.

Aponta-se ainda a necessidade de considerar valores apropriados para cada zona urbanística em função de sua localização topográfica e posicionamento em relação aos ventos dominantes, considerando também a influência gerada pela configuração urbana do entorno. Têm-se como exemplo a cidade de Vitória, cujo posicionamento litorâneo denota que à medida que as quadras se distanciam do mar, o vento marítimo ao se confrontar com a tipologia urbana das primeiras quadras sofre decréscimo em sua velocidade e tem sua direção impactada.

\subsection{Terceira etapa: teste da aplicabilidade do sistema e discussão dos resultados}

O teste do sistema para avaliação do Plano Diretor (ESPIRITO SANTO, 2012) foi realizado para duas zonas urbanísticas do bairro Mata da Praia em Vitória: a ZOC3 (Zona de Ocupação Controlada) e a ZOR/09 (Zona de Ocupação Restrita).

A ZOC3 é composta por 04 (quatro) superquadras localizadas na porção fronteiriça do município, em frente ao mar, e a esta foi aplicado o sistema proposto cujos resultados seguem descritos na Tabela 1.

Para a ZOC3 o Plano Diretor Urbano de Vitória foi considerado adequado, pontuando em $80 \%$ no sistema proposto. A zona apresenta resultados expressivos referentes às questões

Tabela 1: Aplicação do sistema para a ZOC3 do PDU de Vitória (ES)

\begin{tabular}{|c|c|c|c|c|c|}
\hline & QUADRO PARA & $\mathbf{A L}$ & ÇÃ̂O & & \\
\hline & ITEM A SER ANALISADO & SIM & NÃO & ESPECIFICIDADES & PESO \\
\hline 1 & $\begin{array}{l}\text { O coeficiente de aproveitamento (CA) e o gabarito } \\
\text { máximos são estipulados de forma que para alcançar o } \\
\text { máximo em ambos os índices se faz necessário reduzir a } \\
\text { taxa de ocupação máxima permitida }\end{array}$ & $\mathrm{X}$ & & $\begin{array}{l}\text { Não é estipulado CA } \\
\text { máximo, porém é estipulado } \\
\text { o gabarito máx. em } 14 \text { pav. e } \\
\text { TO máx. inferior a } 60 \%\end{array}$ & $15 \%$ \\
\hline 2 & A taxa de ocupação (TO) máxima é menor ou igual a $60 \%$ & $\mathrm{X}$ & & A TO é de $30 \%$ & $15 \%$ \\
\hline 3 & $\begin{array}{l}\text { Prevê dispositivos de redução tributária se a taxa de } \\
\text { ocupação for } 20 \% \text { menor que a máxima permitida por } \\
\text { zona. (Exemplo: isenção do pagamento da taxa de alvará } \\
\text { de construção). }\end{array}$ & $\mathrm{X}$ & & A TO máx. é inferior a $40 \%$ & $5 \%$ \\
\hline 4 & Estabelece valor mínimo para afastamento frontal & $X$ & & Mínimo de 5m & $5 \%$ \\
\hline 5 & $\begin{array}{l}\text { Estabelece valor mínimo para afastamento frontal nos } 3 \\
\text { primeiros pavimentos (incluindo o meio-subsolo) }\end{array}$ & $\mathrm{X}$ & & Mínimo de 5m & $10 \%$ \\
\hline 6 & Estabelece valor mínimo para afastamento lateral & $X$ & & Mínimo de 8m & $5 \%$ \\
\hline 7 & $\begin{array}{l}\text { Estabelece valor mínimo para afastamento lateral nos } 3 \\
\text { primeiros pavimentos (incluindo o meio-subsolo) }\end{array}$ & $\mathrm{X}$ & & Mínimo de 8m & $10 \%$ \\
\hline 8 & Estabelece valor mínimo para afastamento de fundos & $X$ & & Mínimo de 8m & $5 \%$ \\
\hline 9 & $\begin{array}{l}\text { Estabelece valor mínimo para afastamento de fundos nos } 3 \\
\text { primeiros pavimentos (incluindo o meio-subsolo) }\end{array}$ & $\mathrm{X}$ & & Mínimo de 8m & $5 \%$ \\
\hline 10 & $\begin{array}{l}\text { Prevê manutenção de vias que funcionem como canais de } \\
\text { ventilação }\end{array}$ & & $\mathrm{X}$ & & $0 \%$ \\
\hline 11 & $\begin{array}{l}\text { As vias são dimensionadas em função da taxa de densidade } \\
\text { das quadras paralelas a estas }\end{array}$ & & $\mathrm{X}$ & $\begin{array}{l}\text { As vias são dimensionadas } \\
\text { em função da hierarquização } \\
\text { viária constante no Anexo } 3\end{array}$ & $0 \%$ \\
\hline 12 & Identifica a preservação/incentivo de espaços abertos & $\mathrm{X}$ & & $\begin{array}{l}\text { Não para a zona, mas prevê } \\
\text { a manutenção de praças no } \\
\text { interior do bairro (ZPA2) }\end{array}$ & $5 \%$ \\
\hline 13 & $\begin{array}{l}\text { Prevê e/ou incentiva o plantio de vegetação de grande } \\
\text { porte }\end{array}$ & & $\mathrm{X}$ & & $0 \%$ \\
\hline & & & & Quantificação total & $80 \%$ \\
\hline
\end{tabular}


Tabela 2: Aplicação do sistema para a ZOR / 09 do PDU de Vitória / ES

\begin{tabular}{|c|c|c|c|c|c|}
\hline \multicolumn{6}{|c|}{ QUADRO PARA AVALIAÇÃO } \\
\hline & ITEM A SER ANALISADO & SIM & NÃO & ESPECIFICIDADES & PESO \\
\hline 1 & $\begin{array}{l}\text { O coeficiente de aproveitamento (CA) máximo e o } \\
\text { gabarito máximo são estipulados de forma que para } \\
\text { alcançar o máximo em ambos os índices se faz } \\
\text { necessário reduzir a taxa de ocupação máxima permitida }\end{array}$ & & $\mathrm{X}$ & $\begin{array}{l}\text { O gabarito máximo é de } \\
\text { 2pav. }\end{array}$ & $0 \%$ \\
\hline 2 & $\begin{array}{l}\text { A taxa de ocupação (TO) máxima é menor ou igual a } \\
60 \%\end{array}$ & $\mathrm{X}$ & & TO máx. é de $60 \%$ & $25 \%$ \\
\hline 3 & $\begin{array}{l}\text { Prevê dispositivos de redução tributária se a taxa de } \\
\text { ocupação for } 20 \% \text { menor que a máxima permitida por } \\
\text { zona. Como por exemplo, isenção do pagamento da taxa } \\
\text { de alvará de construção. }\end{array}$ & & $\mathrm{X}$ & & $0 \%$ \\
\hline 4 & Estabelece valor mínimo para afastamento frontal & 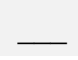 & - & Não se aplica & $0 \%$ \\
\hline 5 & $\begin{array}{l}\text { Estabelece valor mínimo para afastamento frontal nos } 3 \\
\text { primeiros pavimentos (incluindo o meio-subsolo) }\end{array}$ & $\mathrm{X}$ & & & $10 \%$ \\
\hline 6 & Estabelece valor mínimo para afastamento lateral & - & 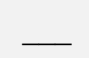 & Não se aplica & $0 \%$ \\
\hline 7 & $\begin{array}{l}\text { Estabelece valor mínimo para afastamento lateral nos } 3 \\
\text { primeiros pavimentos (incluindo o meio-subsolo) }\end{array}$ & & $\mathrm{X}$ & Até o $2^{\circ}$ pav. isento & $0 \%$ \\
\hline 8 & Estabelece valor mínimo para afastamento de fundos & 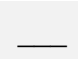 & $\underline{-}$ & Não se aplica & $0 \%$ \\
\hline 9 & $\begin{array}{l}\text { Estabelece valor mínimo para afastamento de fundos } \\
\text { nos } 3 \text { primeiros pavimentos (incluindo o meio-subsolo) }\end{array}$ & & $\mathrm{X}$ & Até o $2^{\circ}$ pav. isento & $0 \%$ \\
\hline 10 & $\begin{array}{l}\text { Prevê manutenção de vias que funcionem como canais } \\
\text { de ventilação }\end{array}$ & & $\mathrm{X}$ & & $0 \%$ \\
\hline 11 & $\begin{array}{l}\text { As vias são dimensionadas em função da taxa de } \\
\text { densidade das quadras paralelas às essas }\end{array}$ & & $\mathrm{X}$ & & $0 \%$ \\
\hline 12 & Identifica a preservação de espaços abertos & $\mathrm{X}$ & & ZPA2: no meio do bairro & $5 \%$ \\
\hline 13 & Prevê e / ou incentiva o plantio de árvores & & $\mathrm{X}$ & & $0 \%$ \\
\hline & & & & Quantificação total & $40 \%$ \\
\hline
\end{tabular}

Figura 3: Zoneamento urbanístico do bairro Mata da Praia / ES

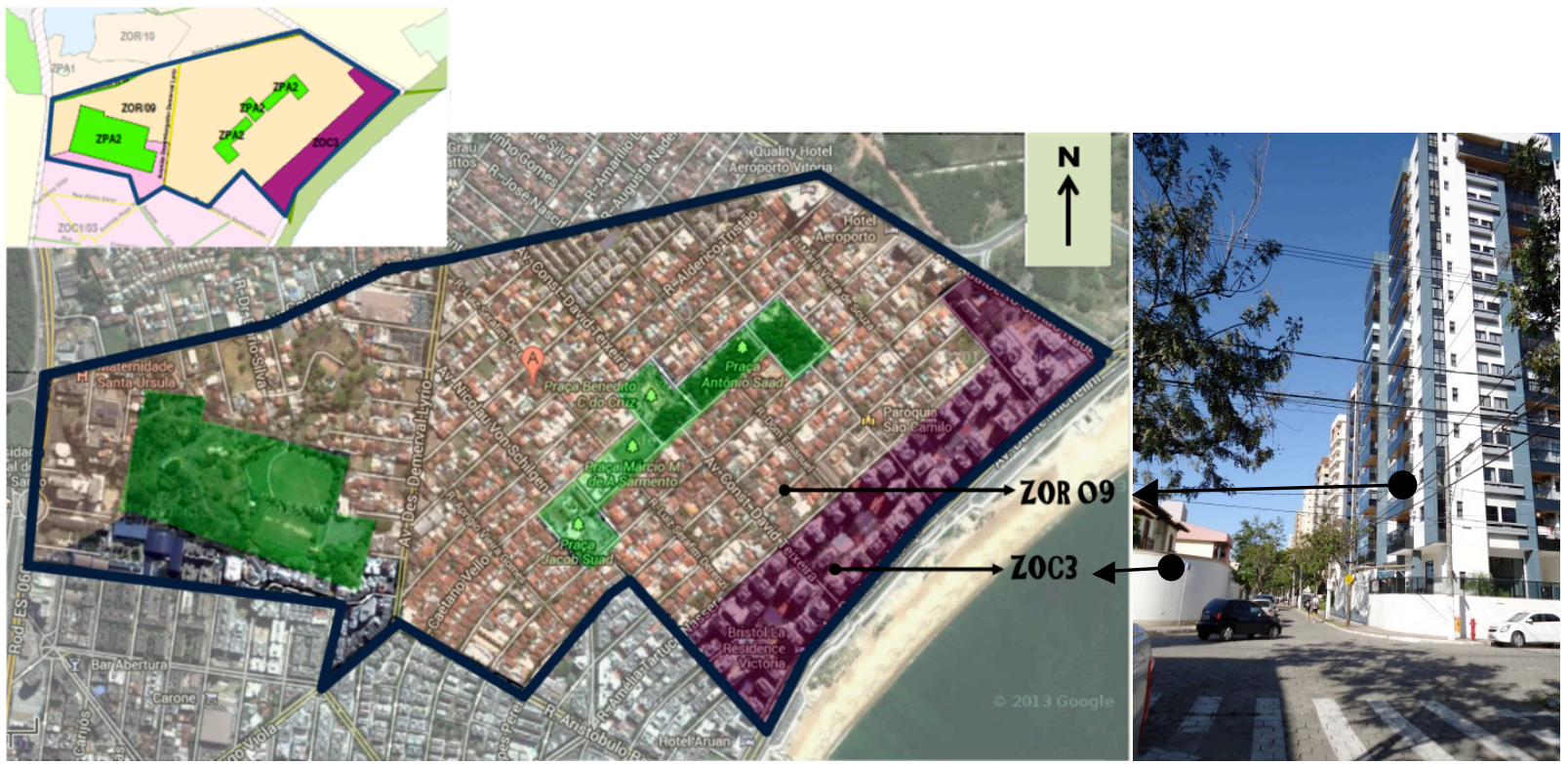

Fonte: Base adaptada do Anexo 2 do PDU de Vitória e de imagem de satélite do google Earth 
de afastamentos e taxa de ocupação, tendo pontuado em todos os itens relacionados a essas duas variáveis. Essas foram identificadas na etapa de revisão bibliográfica como fundamental para garantia da porosidade da configuração urbana e, por conseguinte 0 permeio do fluxo de ventilação natural entre as quadras.

O sistema para avaliação da adequabilidade foi aplicado também para a ZOR / 09, esta está situada na porção interna do bairro, localizada posteriormente à ZOC3 e identificada nas Figuras 3, 4 e 5 . Os resultados obtidos desta aplicação estão descritos na Tabela 2.

Figura 4: ZOR 09
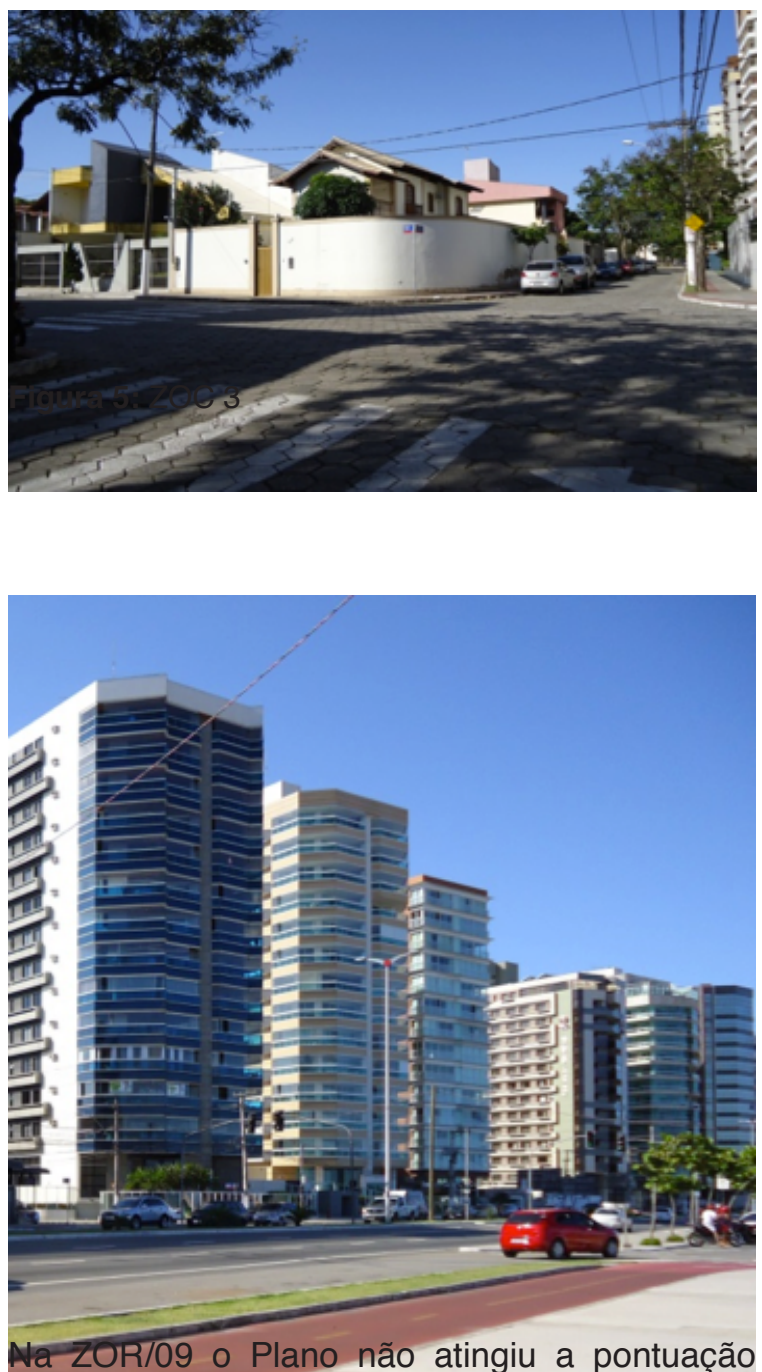
mínima para ser considerado adequado. Nesta zona apesar do baixo gabarito e da taxa de ocupação máxima ser satisfatória, a isenção de afastamentos laterais e de fundos dificulta o permeio da ventilação. Como constatado na primeira etapa o nível do pedestre é o mais impactado pela falta de porosidade, e a ausência de afastamentos laterais e de fundos impacta significativamente no fluxo da ventilação natural.

No PDU de Vitória, assim como na tabela de índices de controle urbanístico da ZOR/09 a maioria das zonas isenta as edificações de afastamentos laterais e de fundos até $02^{\circ}$ pavimento. Essa isenção representa um inconveniente para a ventilação urbana, visto que o gradiente de velocidade do vento decresce à medida que se aproxima do solo. Isso significa que a velocidade do vento é menor nos primeiros pavimentos, e é justamente nesse nível que há a maior necessidade de afastamentos frontais, laterais e de fundos.

A ausência de afastamentos tanto nos primeiros pavimentos como nos demais geram sérias consequências para a cidade, pois dificultam o permeio do vento entre as quadras. Especialmente em uma cidade litorânea como Vitória, é fundamental permitir e incentivar que o fluxo de ventilação marítimo alcance as áreas localizadas no interior da cidade. Esse incremento da ventilação natural deve ser atingido através das distâncias horizontais entre edificações e canais de ventilação.

Observa-se que mediante os resultados obtidos, o PDU de Vitória foi considerado adequado para a ZOC3, contudo não atingiu a margem mínima para ser considerado adequado na ZOR/09. Dessa forma, de acordo com as diretrizes estabelecidas para a utilização do sistema, o plano precisa atingir no mínimo $60 \%$ em cada zona para ser considerado adequado às questões concernentes à ventilação, sendo assim o PDU de Vitória não está adequado.

Como diretriz para ambas as zonas, é importante a identificação das vias que funcionam como canais de ventilação e a implementação das mesmas quando constatadas necessárias, para assim garantir o necessário arejamento citadino.

É indispensável a definição de afastamentos mínimos frontais, laterais e de fundos para todas as zonas, independente do gabarito máximo. Os valores mínimos de afastamentos devem ser estabelecidos em função do gabarito máximo, do posicionamento da zona em relação aos ventos dominantes e do contexto climático de cada cidade.

\section{Considerações Finais}

O sistema para avaliação da adequabilidade do Plano Diretor Urbano aos aspectos relativos à 
ventilação natural urbana demonstrou resultados satisfatórios em seu primeiro teste de aplicabilidade. A aplicação inicial para o PDU de Vitória constatou serem adequados os critérios para utilização do sistema, devendo ser aplicados novos testes para seu aperfeiçoamento. Ressalta-se que os critérios propostos não foram testados em outras realidades climáticas e ambientais, alertando que para a utilização do método para outras localidades é necessária a consideração das especificidades da região.

As ponderações a respeito da atribuição de valores constataram que o método adotado de pontuação única por item, ou seja, só existe a possibilidade de pontuar com valor estipulado ou nulo, impossibilita a atribuição de critérios subjetivos de cada avaliador, auxiliando assim a objetividade da avaliação. Além disso, através da distribuição dos pesos percentuais por item, a inexistência de pontuação em itens constatados como imprescindíveis para o arejamento urbano mostrou inviabilizar que o Plano seja considerado adequado, caso esse não contenha aspectos necessários para a garantia da porosidade urbana.

Dessa forma, reitera-se que apenas com o estudo da realidade local é possível a adoção de soluções bioclimáticas urbanas adequadas regionalmente. Enfatiza-se, por fim, a necessidade de revisão do Plano Diretor de forma a adequá-lo às mudanças decorrentes da expansão urbana, assim como para a identificação dos problemas e benefícios gerados pelas regulamentações contidas no mesmo. Sendo assim, o PDU não deve ser um instrumento estático, mas sim flexível e adaptável às transformações urbanas, e estar alicerçado em critérios de adequabilidade bioclimática.

\section{Agradecimentos}

À CAPES (Coordenação de Aperfeiçoamento de Pessoal de Nível Superior) pela bolsa de mestrado.

\section{Referências}

ALCOFORADO, M. J.; ANDRADE, H. Clima e Saúde na cidade. Implicações para 0 ordenamento. In SANTANA, P.. A cidade e a saúde. Ed. Almedina, Coimbra, 2007.

BRASIL. Constituição (1988). Constituição da República Federativa do Brasil: promulgada em 5 de outubro de 1988. Disponível em: <http:// www.planalto.gov.br/ccivil_03/constituicao/ constituicao.htm>. Acesso em 15 jan. 2013.

BRASIL. Lei ${ }^{\circ} 10.257$, de10 de julho de 2001. Regulamenta os arts. 182 e 183 da Constituição Federal, estabelece diretrizes gerais da política urbana e dá outras providências. Diário oficial [da] República Federativa do Brasil. Disponível em: <http://www.planalto.gov.br/ccivil_03/Leis/ LEIS_2001/L10257.htm>. Acesso em 23 abr. 2012.

CÂNDIDO, C.; BITTENCOURT, L.. Introdução à ventilação natural. Maceió: EDUFAL, 2008.

ESPÍRITO SANTO (Estado). Lei $n^{\circ} 6.705$, de 13 de outubro de 2006. Institui o Plano Diretor Urbano do Município de Vitória e dá outras providências. Prefeitura de Vitória. Disponível em:<http://sistemas.vitoria.es.gov.br/webleis/ consulta.cfm? $\mathrm{id}=167650>$ Acesso em 18 jun. 2012.

GARTLAND, L. Ilhas de calor: como mitigar zonas de calor em áreas urbanas. São Paulo: Oficina de textos, 2010.

GRIMMOND, C. S.B.; OKE, T.R. Aerodynamic Properties of Urban Areas Derived from Analysis of Surface Form. Journalofappliedmeteorology, volume 38, páginas 1292 - 1292, ano 1999.

HIGUERAS, E. Urbanismo Bioclimático. Barcelona: Gustavo Gili, 2006.

INMET. Instituto Nacional de Meteorologia: Dados Históricos. Disponível em: <http://www. inmet.gov.br/portal/index.php?r=bdmep/ bdmep>. Acesso em 15 mar. 2013.

LOPES, A.; VASCONCELOS, J. A influência da morfologia urbana na modificação das brisas do estuário do Tejo na zona oriental de Lisboa. Lisboa, 2006

LEITE, C. G.. Alterações da ventilação urbana frente ao processo de verticalização de avenidas litorâneas: o caso da Avenida Litorânea de São Luís / MA. Dissertação de Mestrado -PPGAU, Faculdade de Arquitetura e Urbanismo de São Paulo, 2008.

MARQUES, R. S. Ventilação e Prescrições Urbanísticas: uma aplicação simulada para a Orla da Praia do Meio em Natal / RN. 2003. Dissertação de Mestrado - PPGAU, Universidade Federal Do Rio Grande do Norte, 2003.

MASCARÓ, L. Ambiência Urbana. $2{ }^{a}$ edição Porto Alegre: + 4 Editora, 2004. 
OKE, T. R. Initial guidance to obtain representative meteorological observations at urban sites. World Meteorological Organization, Instruments and Observing Methods, Report $\mathrm{n}^{\circ} 81, \mathrm{n}^{\circ} 1250$. Canadá: WMO/TD, 2006.

ROMERO, M. A. B. Princípios bioclimáticos para o desenho urbano. Editora: CopyMarket.com, 2000. 